\title{
El sonido musical de Victoria Poleva en articulación con la imagen fílmica de Andrei Tarkovsky ${ }^{1}$
}

\author{
Ricardo Espinoza Lolas, \\ Pontificia Universidad Católica de Valparaíso, Valparaíso, Chile \\ respinoz@ucv.cl
}

Boris Alvarado

Pontificia Universidad Católica de Valparaíso, Valparaíso, Chile boriska02@hotmail.com

Patricio Landaeta Mardones

Centro de Estudios Avanzados, Universidad de Playa Ancha, Valparaíso, Chile patricio.landaeta@upla.cl

\begin{abstract}
Resumen: El artículo pregunta por la articulación esencial entre el arte de Victoria Poleva y Andrei Tarkovsky. En ambos artistas se da algo único en su mutua diferencia. Tanto en el sonido de Poleva como la imagen de Tarkovsky acontece en un cierto cuerpo y espacio de la inmanencia y la materialidad que nos abre a lo otro. Es una arquitectura del espacio (lo profano se vuelve sacro) y una escultura del tiempo (la eternidad en el instante). Creemos que en la materialidad sonora de Poleva podemos encontrar ese bellísimo trabajo del esculpir el tiempo tan propio del cineasta ruso. Poleva es la arquitecta y escultura del sonido y su sonido abre la realidad. Y nos posibilita a veces poder dar con un espacio tiempo propio para cada uno de nosotros. Por esto este artículo interroga por la materia y el espaciotiempo como elementos fundamentales para dar con lo propio de este arte sacro minimalista contemporáneo. Y para esto nos servirán ciertas categorías fundamentales de filósofos contemporáneos; por ejemplo, de Nietzsche, Heidegger, Deleuze, etc. Con estos conceptos se podrá expresar el arte de nuestros artistas.
\end{abstract}

Palabras clave: Tarkovsky; Poleva;Deleuze; Zubiri;materia; sonido e imagen.

The musical sound of Victoria Poleva in articulation with the film image of Andrei Tarkovsky

Abstract:The article questions the essential link between the art of Victoria Poleva and Andrei Tarkovsky. Both artists are given unique in their mutual difference. Both sound and image Poleva Tarkovsky happens in a certain body and space immanence and materiality that opens us to the other. It is an architecture of space (the profane becomes sacred) and a sculpture of time (eternity at the moment). We believe in sound materiality of Poleva we can find this beautiful work of sculpting time peculiar to the Russian filmmaker. Poleva is the architect and sculpture of sound and its sound opens reality. And sometimes it enables us to give a space the same time for each of us. Hence this article inquires into the matter and spacetime as fundamental elements to it own this minimalist contemporary sacred art. And for this they will serve certain fundamental categories of contemporary philosophers; for example, Nietzsche, Heidegger, Deleuze etc. With these concepts can express the art of our artists.

Keywords:Tarkovsky; Poleva;Deleuze; Zubiri; matter; sound and image.

O som musical Victoria Poleva em coordenação com a imagem do filme de Andrei Tarkovsky

Resumo: O artigo questiona a ligação essencial entre a arte de Victoria Poleva e Andrei Tarkovsky. Em ambos os artistas se dá algo único em sua diferença mútua. Tanto o som de Poleva quanto a imagem de Tarkovsky acontece em um certo corpo e espaço da imanência e a materialidade que nos abre para o outro. É uma arquitetura do espaço (o profano se torna sagrado) e uma escultura do tempo (a eternidade no momento). Nós acreditamos que na materialidade sonora de Poleva podemos encontrar este belo trabalho de esculpir o tempo tão peculiar do cineasta russo. Poleva é a arquiteta e a escultura do som e o seu som abre a realidade. E às vezes isso nos permite dar um espaço-tempo para cada um de nós. Por isso este artigo investiga a matéria e espaço-tempo como elementos fundamentais para o seu Inventário de arte sacra contemporânea minimalista. E, para isso, nos servirão certas categorias fundamentais dos filósofos contemporâneos; por exemplo, de Nietzsche, Heidegger, Deleuze etc. Com estes conceitos poderemos expressar a arte de nossos artistas.

Palavras-chave: Tarkovsky; Poleva; Deleuze; Zubiri; matéria; som e imagem. 


\section{Introducción}

¡Poleva! iSimplemente, Poleva! ¿Una tautología vacía? En absoluto. ¿Quién es Poleva como artista ucraniana y contemporánea para nosotros? ¿Qué es lo propio del arte de Poleva? En realidad, Poleva no es solamente una compositora contemporánea y ucraniana, de Kiev, cercana al horizonte compositivo de Arvo Pärt y dedicada al arte sacro minimista. iPoleva es más que eso! Lo mismo que Andrei Tarkovsky, quien no fue simplemente un cineasta ruso que hizo solo siete films que han quedado en la historia del cine. iTarkovsky es más que eso! Poleva es simplemente sonido y Tarkovsky es simplemente imagen.

Es como una tautología del sonido y de la imagen, pues el sonido en su carácter físico sonoro y la imagen en su carácter físico visual, desbrozan y abren desde sí mismos la realidad (natural, individual, social e histórica) (ESPINOZA et al. 2014). Pero ¿cómo acontece semejante sensación sonora de Poleva? Y no estamos hablando desde un carácter de la fe de un creyente determinado, ya sea el propio artista, ya sea el público (estamos en un plano anterior a la propia fe); sino que estamos en la propia materialidad sonora; independiente de creencias o no, acontece lo otro en ese sonido compuesto por Poleva; es lo que llamamos el "sonido Poleva"; y en este sonido se abre la trascendencia ya para creyentes, ateos, agnósticos, etc. El "sonido Poleva" abre en la propia materia sonora lo inespecífico de lo Otro y en esto el público puede elevarse y sentirse desbrozado radicalmente en su propio cuerpo. El artista con su obra forja "espíritu" en elpropio cuerpo de cada uno de nosotros. El cuerpo desbrozado se repliega infinitamente y allí se da la posibilidad física de volvernos espirituales. Poleva, Pärt, Tulev, Grigorjeva,Tarkovsky, Ozu, Kurosawa, Rothko, Bacon, Celan, Donne, Blacke, Nietzsche, Beuys, Cartier-Bresson, Viola, etc. son artistas que le han dado, literalmente, al hombre un espíritu en donde vivir y así experienciar la naturaleza en su más grande apertura.

\section{1. ¿Quién es Poleva?}

En la sensación sonora que crea Victoria Poleva se da algo similar a lo que acontece en la imagen de Tarkovsky, cuando en la ralentización auto contenida del plano en su dimensión inmanente temporal nos lleva de la mano a la eternidad, desde ese mismo plano temporal en que esculpe el tiempo (TARKOVSKY, 2008). Pues la imagen no nos lleva por fuera de ella, al igual que el "sonido Poleva" en su obra para violín solo y orquesta de cuerdas Pieta (POLEVA, 2006-2012), no nos lleva por fuera de la propia obra: el mismo sonido espacia o abre espacio y construye realidad. En ese abandono del afuera es cuando Poleva da lugar a su propio sonido, al "efecto Poleva”, que va más allá de la música como resultado sonoro. Porque en esta condición ella logra percibir, libre de formas narrativas y de lenguaje, el sonido en su forma más primitiva, como una pura vibración, y con ello, encontrarse con el sonido puro, libre y desgarrado de todo sistema, deviniendo en nuevos sonidos.

Imagen y sonido se despliegan en lo que ellos mismos, nada representan por fuera de su propia materialidad sensitiva. No es necesario "explicar" el cine de Tarkovsky (a veces el gran pecado inaceptable de Cahiers du Cinéma) ni la música de Poleva; sino que hay que sumergirse en su propio arte y desde él abrirse a la experiencia de la materialidad y trascendentalidad de la sensación. En Poleva, por ejemplo, se trata de pasar del fenómeno artístico a la captura del sonido puro, sin dejar actuar los filtros de la concepción musical y el arte occidental. De esta manera, el sonido resulta ser una yuxtaposición que se caracteriza por la síntesis de la estructura y los valores de regularidad, en su sentido rítmico, a la manera de un continuo. Luego antes que obra, encontramos el sonido en un estado anterior 
a la que se expresa en su integración en un obra acabada.

Este hecho nos lleva a afirmar que ya no es necesario explicar narrativamente lo que expresa una imagen tarkovskiana,como lo hacen algunos especialistas (LLANO, 2003) o un sonido poleviano. Es tan fundamental quedarnos en la materialidad del arte de nuestros artistas, que es interesante señalar que tanto el cineasta ruso como la compositora ucraniana se sumergen en las tonalidades propias de su tierra y de sus elementos originarios (junto con su fe). No podemos experienciar sus obras sin, por ejemplo, vivenciar lo que expresa el agua, la tierra o el fuego (elementos naturales)para ellos. Y desde esos elementos propios que emergen de sus tierras natales van esculpiendo su arte en el tiempo mismo. Tanto el cine como la música constituyen la aventura titánica de una arquitectura del espacio (nos falta un verbo en castellano para nombrar la arquitecturain actu exercito; sería algo así como,usando un barbarismo, “arquitecturar”) y de un esculpir tiempo en la materialidad de la sensación. Y ambas formas, sonido-imagen, de arquitectura-escultura, indican una cierta totalidad que se abre desde un gesto sensitivo físico concreto. Una totalidad abierta del sonido y otra desde la imagen con sus peculiaridades sensitivas determinadas. Pues no es lo mismo cómo acontece la materialidad en la sensación sonora y cómo lo hace en la imagen. La materia en la imagen acontece en ocasiones en la detención del plano secuencia y en la ampliación del zoom, sosteniendo la imagen y dejando que se muestre "eso"; en cambio, en el "sonido Poleva" de Metta -in modo Pärt- (POLEVA, 2009) a veces se da la materialidad en el silencio que queda "entre" el sonido en su vibración elevada (y sus contrapuntos) y en el volver a iterar dicho sonido. Pero siempre depende de la obra, de la materialidad de la obra en el cuerpo del artista y el cuerpo de los que la experiencian en cierto espacio-tiempo. Se produce aquí, entonces, algo así como una paradoja del sonido desde la escritura, la que pretende siempre decir o connotar, pero aquello que connota no siempre se subordina a la significación de los signos que se emplean, y que luego deviene en un tiempo impredicible, una escritura del tiempo irracional en el cual el proceso es el tiempo que tiende siempre a desbordarse, a escurrirse de la medida, donde el tiempo parece escaparse del tempo. Con ello, la unidad de tempo, tan fundamental para concertar sincronizadamente a los interpretes, se relativiza desconcertandolos en el sentido de que ya no es un solo tempo que ocurre en un solo momento. Es una música como torrente que recorre y fluye de manera acotada. Un río de tiempo que tiene la particularidad más bien de convertirse ahora en una politemporalidad, para desdoblarnos en múltiples corrientes, que tienen la facultad de superponernos, que determinan no solo el tiempo ordinario(el tiempo que va pasando, y al ir pasando hace desaparecer lo de antes, haciendo emerger lo nuevo), sino también determina el tiempo de la propia música humana.

El sonido y la imagen articulados se complementan en sus creadores y dan de sí un mundo, un mundo completamente real "en medio de éste", mundo tardo-capitalista en el que nos subjetivamos penosa y pobremente.

\section{Sensación sonora y fílmica}

En estos tiempos que corren es imposible no pensar en un "rizoma" o, lo que sería más adecuado pensar, como refieren Deleuze y Guattari, "rizomáticamente” (DELEUZE; GUATTARI, 2000, p. 9-29). Este tipo de pensar mienta simultáneamente diferentes modos de articular la realidad, sin una raíz determinada y que, a la vez, en sus múltiples referentes y en sus entrecruzamientos, van dando de sí lo que se quiere mentar en este artículo; por ejemplo, sonidos e imágenes; música y cine. Poleva y Tarkovsky. Y así acontece el sentido buscado, en nuestro caso la materia en su expresión fílmica-musical de la imagen-sonora 
tanto del cine como de la composición musical. Pero para llegar a hablar tanto del sonido como de la imagen debemos movernos primeramente en algunas categorías conceptuales de algunos filósofos que nos permitan dar con una concepción de la materia y del espacio-tiempo que nos dejen ad portasdel sonido y la imagen. Sin embargo, con este pensar rizomáticamente no debemos caer en delirios o locuras, pues estos ya se nos volvieron en otra dimensión metafísica de un cierto "envío" (Geschick des Seins diría el segundo Heidegger de los años 30 y de sus ya célebres Beiträge zur Philosophie) que descansaba una vez más en tristes y trasnochadas microfísicas del poder, voluntades institucionales, voluntades "puras y originales", voluntades de mercado, voluntades en el horizonte ontológico de la "presencia y presente" (Anwesenheit y Gegenwart) dicho en términos de Zeit und Seinde 1962 (HEIDEGGER, 1999, p. 20-27). No queremos pensar de modo ontológico ningún tipo de "envío" (de nada ni de nadie), el que fuere, para dar cuenta de la materialidad del sonido y de la imagen; menos generar relatos de "otro mundo" para narrar y representar las obras de estos artistas de lo sacro (Poleva y Tarkovsky). En tal horizonte heideggeriano que fue clave en el siglo XX no podíamos salir de que las cosas "son" y en ese ser de las cosas todo se presentaba a luz de un horizonte que permite su presencia, su aparecer $\mathrm{y}$, a la vez, que se hace visible a la luz del presente en el que se está, por eso la presencia y el presente en su mutua co-pertenencia dan de sí a lo ente (ibidem); lo ente se nos vuelve en lo presente que es así, con un espacio propio (y su antípoda impropia), un tiempo propio.

De este horizonte de pensamiento no se puede salir y nos quedamos atrapados al análisis fenomenológico; y así no se puede vivir, no se puede innovar, transformar, no se puede crear, ni producir, ni nacer, ni morir ya sea de modo impropio, sin embargo tampoco en el sentido propio se encuentra alguna salida, pues no somos solamente entes que son a la luz de la co-pertenencia entre presencia y presente, sino que hay realidad, materialidades, estofas, sensaciones, capaz de pasado, historias, memorias, dispositivos, juegos, etc. (DUQUE, 2000)

Y por esto los artistas, los de "verdad", nos llevan por medio de sus obras a la materialidad misma de las cosas y en ello acontece lo otro. Con los relatos metafísicos, fenomenológicos, científicos, tecnológicos, políticos nos faltan las dimensiones materiales, corporales, psicológicas, históricas, azarosas, etc. del acontecimiento de la vida. Y empero cuando acontece la vida, en toda su expresión sensitiva (sonidos, imágenes, colores, etc.), ésta se nos ha vuelto en un "pliegue", una mónada que en sí misma se nos despliega, se nos expresa en lo que nos cierra y, a la vez, nos abre y produce mundo en tramas rizomáticas de otros pliegues y que aparece luego en el análisis fenomenológico heideggeriano en ese aparente e inocente mostrarse de lo ente a la luz de la presencia y del presente; entonces en ese pliegue, en eso an und für sich, dicho en términos del primer Hegel de la Fenomenología del espíritu de 1807, que no se soporta en nada distinto que ser mero an und für sich (1966, p. 7-48),podemos tener los supuestos mismos de todo aparecer y que posibilita entender la materialidad de ese aparecer y de ahí todo tipo de producción y creación de nuevas formas de habitar.

El arte crea nuevas formas de habitar. Y por eso en el arte se da la posibilidad de poder agenciar un cambio no solamente de la propia subjetividad sino de la sociedad entera e incluso a nivel histórico. Esta era la gran apuesta de Tarkovsky (y lo fue de Nietzsche, Deleuze y tantos otros). iNecesitamos el arte! La obra nos da la posibilidad de recrear en la misma materia a eso otro que nos permite vivir mejor. iEl arte hace bien! iY el arte de Poleva mejor! Y en esto ella es una maestra. Eso en y por sí mismo que se indica como momento que expresa el todo, por ejemplo, en el sonido o la imagen (más que el algoritmo técnico actual) podemos ver y escuchar mejor, que en cualquier marco teórico conceptual, cómo se 
da el espacio y el tiempo del plano fílmico o del sonido para que se dé el otro en tanto que Otro y así una forma de vida más plena y jovial.

Las imágenes en cuanto esas mismas imágenes (lo mismo respecto de los sonidos) van generando un rizoma de imágenes, es una trama, una historia "natural” de la imagen. No hay una historia metafísica, ni teológica, ni política de la imagen; es la propia imagen la que va generando su historia en una concatenación de imágenes. Y en esta historia se produce vida, horizonte para ser y realizarce. Y luego el mismo hombre va contando historias oficiales por fuera de esa imagen (un relato siempre ideologizado). Pero esto es siempre posterior a la sensación de la propia imagen. Por lo señalado pensemos en una Imagen, en una Historia de unas imágenes o la Historia del cine , dicho al estilo de Jean-Luc Godard (GODARD, 1988), de una imagen cualquiera del cine y lo mismo habría que hacer como una Historia de la música, de la sensación sonora. Esto todavía no se ha hecho. Y creo que es un escándalo para la música. A lo mejor Poleva pueda generar una obra musical (así como Godard lo hizo para el cine) que nos cuente la historia de la sensación sonora; no un relato metafísico ideológico de la música. Y en ello a lo mejor albergamos la posibilidad de esa historia "natural" del sonido y que podamos producir un mundo para el hombre actual. La conexión entre sí de los sonidos a lo largo de la historia en cuanto carácter sensitivo sonoro nos puede abrir a un horizonte insospechado de la totalidad. Aquí hablaremos de una imagen especial, de Tarkovsky, al final de este artículo, pero indicaremos también otras imágenes que nos permitan sentir los sonidos de Poleva.

iY si no fuéramos más que vibraciones, resonancias, acoplamientos, cuerpos, cuerpos sonoros, presencias sonoras, si no fuéramos más que sonidos e imágenes! (así como lo piensa Bergson explícitamente para la imagen ya en 1896 en Materia y Memoria (2006, p. 33-87)). Por ejemplo, Psalm 50 de (POLEVA, 2000). En esta obra se da el acontecimiento del sonido y en la expresión sonora de la voz quedamos cautivados, arrebatados y elevados. ¿Por qué? Porque obviamente que no es el Salmo propiamente tal el que nos convoca; no es la narratividad, por ejemplo, de la culpa lo que nos interesa, tampoco la misericordia de Dios; ni menos lo que nos conmueve, sino el sonido que está en esos relatos. El "sonido Poleva". ¿Qué hay en el "sonido Poleva" que nos hace vibrar a nosotros mismos y nos vuelve espiritual? ¿Cómo acontece ese sonido que nos espiritualiza? ¿Cómo se da la espiritualización del hombre en la materialidad sonora de Poleva? Sonido, voz, voces (de la culpa y de la misericordia), escalas, ralentización, vibración, acoplamiento, silencio, iteración, expresión de fuerzas, elementos de precisión sonora, carácter envolvente y gradual en una melodía hacia un punto fundamental y a la vez en despliegue triádico (en que se entrecruza lo gradual), tensión de las partes en el todo.

Su obra nos trae también a la memoria los vídeos de Bill Viola: Passage, The Passing, The Crossing, etc. Por eso el autor estàn claro en señalar: "Estamos dejando atrás los modos propios de la imprenta y de las letras y entrando en el mundo de la imagen: abandonamos el razonamiento deductivo y nos dirigimos a modelos de tipo asociativo" (VIOLA, 1995, p. 243). O la imagen plano secuencia de Tarkovsky de un hombre intentando pasar en la madrugada por una terma vacía perdida en Bagno Vignoni (Italia) de un extremos al otro llevando encendida una vela (este es el plano por excelencia de Notalghia (TARKOVSKY, 1983); en ese plano como en Psalm 50 acontece la materialidad de la tierra elevada con el viento al fuego (volveremos al final del texto sobre esto). Es la materia la que se abre a sí misma en ese "sonido Poleva"; cual vela encendida que buscar eternizar en el instante; y a la vez sonido eterno retornante y jovial, como diría Nietzsche (2009). En tal materialidad del sonido acontece lo otro y así se nos produce mundo y se nos invita a vivir en él, como acontece en su obra acerca del texto Meditation XVII de John Donne par solistas, coro, piano 
y cuerdas (No man is a island) (POLEVA, 2006).

Un sonido y una imagen, en trama rizomática, con otros múltiples sonidos e imágenes, que expresan en un instante una cierta totalidad, en su propia materialidad, que no quiere ser total sino abierta siempre a una nueva interpretación. Veamos, por ejemplo, cómo nos muestra el cineasta Wong Kar-Wai en el plano final de In the mood for love(2000) lo que estamos señalando, esto es, en un espacio, un espacio corporal determinado (en este caso sagrado como todos los espacios de las obras de Poleva) ante la presencia de un joven monje y ante un hombre que quiere continuar con su vida pese al dolor del amor por una mujer que aparentemente no le correspondió (y para eso debe hacer el ritual del despido, del olvido de ese dolor en las ruinas de un monasterio, dejar su secreto cubierto en algún lugar de ese templo), pues no hay espacio que no sea determinado por un cuerpo (cuerpo y espacio van siempre de la mano (ESPINOZA et al. 2014), un atemperamiento, un afecto; ahí mismo, en ese espacio corporal que muestra la imagen (donde la propia imagen es ese espacio corporal de lo sagrado y además sonoro de Shigeru Umebayashi) se cruza una mónada, un pliegue, una nueva imagen que no configura del todo, que no puede dar con un cuerpo acabado total y que se nos vuelve en secreto, nuestro secreto, una cierta opacidad propia del cuerpo, del espacio corporal que indica la imagen y tal cuerpo es la imagen misma que da sentido a todo el film y allí mismo el tiempo. Es interesante recordar la obra de Poleva titulada Gagaku (1994). En esta obra podemos ver algo semejante a lo que hemos descrito de la imagen fílmica.

El cuerpo siempre de la mano del espacio y del tiempo y que la imagen y el sonido sabe indicar, eso es, Poleva y Tarkovsky. Las obras de Poleva en su construcción son arquitectónicas, "espacian” el territorio y luego lo interiorizan temporalmente; sus obras son bellas y únicas grandes catedrales voluminosas o pequeñas capillas minimalistas que vibran en su interior. El tiempo de su obra da de sí; da de sí cualquier modo de medirlo y cogerlo (atraparlo); en esa topología radical de la "Y", que cruza a ese espacio "Y" a ese otro, se da una oportunidad para diferir, para demorarse, para quedarse en ese secreto que nunca comienza porque nunca termina, en esa cierta resistencia de la imagen, del cuerpo en su opacidad que nunca se da del todo al análisis fenomenológico, pero en el que siempre estamos siendo mientras estamos siendo, se nos da la oportunidad radical de experimentar instantes joviales que nos hundan en el ocaso o que nos levanten bajo el mediodía; es, como se sabe, los rasgos propios del eterno retorno para Nietzsche (2005), la sensación en su instante que abre eternidad; eso es la obra arquitectónica y escultórica del "sonido Poleva”. El fenómeno de sonido debe estar libre de imposiciones formales, artísticas. Sus estructuras y formas, en el sentido musical, no proceden de un origen artístico, sino de una sincronización vibratoria entre transcriptor y la composición escrita y entre este trabajo y el que escucha o, simplemente, lo escucha. Sólo el puro acto de meditación del transcriptor, se sincroniza con el arquetipo de la voluntad de los formularios, puede capturar los sonidos que llevan los receptores de los sonidos de nuevo a sus valores originales,primordial.

La vida, esa vida radical, nuestra vida carnal se cruza y se entrecruza y es en sí misma nada más y nada menos que ese entrecruzamiento que nos liga, nos ata y nos lanza inexorablemente a quedarnos, simplemente quedarnos en múltiples viajes (como las composiciones de Poleva o los planos de Tarkovsky), viajes que no comienzan ni terminan, viajes como los que muestra el Film 2046 (KAR-WAI 2004), hacia y desde el 2046; viajes fragmentarios de rumbos y rutas que nos sugieren como la novela Flashback. Miradas y gestos (ESPINOZA, 2012), en el instante, posibles nuevas mediaciones para seguir en ellas mismas a algún lugar que nos convoque a morar y a enamorarnos nuevamente como si fuera la primera vez. 


\section{Materia creativa}

Materia y Otro. iUn Cruce!. Todos los conceptos devienen, son sentientes, impresivos, físicos, Centauros (NIETZSCHE, 2007) intentan expresar lo que nos impresiona y se nos impone. Y en tanto que surge de la impresión afectante, el concepto es una libre construcción que en el lenguaje intenta interceder, abrir, comunicar, acompañar, liberarcomo diría Zubiri (1982). Heidegger al final de su vida nos dice explícitamente que: "Espaciar es libre donación de lugares [Räumen ist Freigabe von Orten]” (HEIDEGGER, 2003, p. 125-127). Y esto lo logra con todo el arte; no solamente la plástica como lo piensa Heidegger, sino también el cine y, en especial, la música. Materia y Otro no es cuestión de conceptos, sino de rizomas que se entrecruzan; no en dialécticas, sino como lo diría Arvo Pärt a la "Tintinnabuli” (HILLIER, 1997, p. 87); rizomas que los artistas saben comprender con sus obras y que a los filósofos les cuesta años y años para simplemente tocar por medio de conceptos tangencialmente lo que indican. La materia es uno de esos rizomas más antiguos que nos acompañan desde siempre a eso otro que llamamos a veces simplemente hombre o, si se quiere, nada más que Otro; en la materia vamos corporizando nuestro caminar.En y por el cuerpo vamos viviendo y así nos vamos volviendo, en una primera instancia, en meramente Otro, pero un Otro que somos cada uno en el caminar de la cotidianidad. iSí!, la materia nos vuelve Otro desde lo más íntimo y material que somos; eso que desde antiguo se asoció con la idea de espíritu (Spiritus, Geist) es el resultado, es el precipitado de nuestra "carne" agradecida por la instantaneidad que se abre en ella (es La eternidad y un día como lo diría Theo Angelopoulos (1998),materia y Otro, en ese espacio arquitectónicamente construido y ese tiempo esculpido. La cuestión es la "Y” que los articula y los pone en juego (la articulación entre lo melódico y lo triádico en la música de Poleva); que los coloca a resonar el uno en el otro. Tratemos aquí y ahora de pensar someramente esa "Y" rizomática desde el arte de Poleva y Tarkovsky; aunque ya lo hemos señalado, en el fondo es un trabajo con la materia, con los materiales, con las estofas, las sensaciones que nos permite habitar lo sagrado en un espacio-tiempo propio.

Lo que nos convoca esta meditación en torno a Poleva y Tarkovsky es la "Y", el cruce que da de sí al hombre y su cuerpo, al hombre y su espacio-tiempo (esto es, el sonido y la imagen) o, si se quiere, esa materia que da de sí al hombre, a ese hombre determinado desde ese cuerpo y determinado en su corporizar, determinado en su más radical inquietud, dinamismo, borrosidad; así como uno de esos tantos ensayos plásticos de Bacon que son solamente en la borrosidad de su propio límite que siempre están transgrediendo, en transfinitud, en el mero acontecimiento expresivo.

¿Qué somos? iPorciones de espacio-tiempo! iPorciones de imágenes sonoras! iPorciones en transfinitud! iAcontecimientos! iVibraciones! iBorrosidades! Zubiri diría que somos momentos articulados unas con otras (ZUBIRI, 1996). Unas notas que se actualizan las unas a las otras y en esa co-actualidad, activa en y por sí misma, se da de sí el Otro, en ese espacio-tiempo de excedencia de las propias cosas se convoca al Otro; el Otro cobra asiento e intenta señorear desde lo más radical de su propio imponerse que nos fuerza a dejarnos con la boca abierta para que así podamos construir algún concepto o ficto o afecto a la altura misma de eso Otro. Esa conectividad, esa co-actualidad es la que en su hacer Poleva puede darnos una Historia de los sonidos y en la medida que sigue componiendo es posible que podamos ver cómo sería la sensación sonora en su propia historia sonora. Y ahí mismo es posible que podamos asistir a otro modo de vivir en torno al Otro. Y esto está en juego en cierto arte, no en cualquiera, ni menos en cualquier artista; el arte de Poleva (el "sonido Poleva”), arte productora de espacios sagrados como capillas o catedrales como en su traba- 
jo sinfónico Null (POLEVA, 2006) o de sus majestuosos coros como el Salmo 22 (POLEVA, 2001) y de tiempos propios que se van dando en la materia de su sonido en el ejecutar del mismo. Su obra siempre es in actu exercito (el acto de la obra lo es todo), así como un Miguel Ángel, es allí en esa arquitectónica del espacio y esculpiendo el tiempo es que se produce mundo y sentido para habitar. Un Miguel Ángel a la vez arquitecto como escultor, eso es el "sonido Poleva". Y con la fuerza para levantar o la Cúpula de San Pedro o para esculpir el detallado y fino brazo de su Moisés. Por eso la obra de Poleva estremece a cualquiera, nadie es indiferente a su arte y en cualquier lugar de este mundo. No hay territorio que se le resista: ni físico, ni virtual, ni inconsciente.

\section{Imagen y sonido creador de mundo}

Para poder entender más acabadamente lo señalado debemos preguntarnos someramente: ¿Qué mienta esa "co-extensividad" entre materia-sonora-imagen y Otro? Todo lo real tiene de alguna manera una referencia a la materialidad piensa Zubiri (2006).¿Qué es esa materialidad del cuerpo sonoro de Poleva y de la imagen de Tarkovsky? La materialidad (esto es, una mera trama de momentos) es lo que posibilita y constituye una materia y Otro; si se quiere, se podría decir, al modo kantiano, que la materialidad es la condición de posibilidad de cualquier tipo de materia y Otro: ya sea un cuerpo geométrico (cuerpo libremente construido para diseñar geometrías), ya sea un cuerpo físico (cuerpo que se impone en y por sí mismo para que se mueva el móvil), ya sea un cuerpo político (cuerpo creado en la propia sociedad), ya sea un cuerpo visual (cuerpo creado por el artista para expresar), etc. La materialidad es un modo de articular, de estructurar; las distintas materias (colores, sonidos, imágenes, etc.) son las estructuras que se dan en ese materializar de la materialidad; aquí se puede ver cómo acontece la melodía dominante que permite la territorialización del espacio.

Einstein, como otros del siglo XX, fue uno de los grandes innovadores de la idea de espacio-tiempo y, por ende, de la materia, del sonido y de la imagen; es cosa de pensar visualmente su concepción teórica de la Relatividad (ya la General como la Restringida). En él se da toda una concepción de la "Imagen de la Naturaleza" que abre en el siglo XX una nueva "Imagen de la Materia”. No olvidemos que todos estos físicos y matemáticos discutían contra la concepción de espacio absoluto propuesto por Newton que se les volvió en un horizonte de comprensión asfixiante (lo mismo pasó con la filosofía); en donde las cosas solamente “ocupaban” un lugar determinado. Señala Einstein (1990):

La sutileza del concepto de espacio fue realzada por el descubrimiento de que no existen cuerpos completamente rígidos. Todos los cuerpos son elásticamente deformables y alteran su volumen con cambio de temperatura. Las estructuras, cuyos posibles configuraciones habían de ser descritas por la geometría, no pueden ser caracterizadas, por consiguiente, sin referencia a la física. (p. 331)

Esto es brillante en Einstein; ahora ya se habla hasta de cuerpos deformables, elásticos y esto es una tremenda concepción física de la imagen y también del sonido que está presente en todo el arte de siglo XX y continúa presente hoy; por ejemplo, es imposible entender la pintura de Bacon o el cine de Godard sin este marco conceptual de Einstein y tampoco la imagen de Tarkovsky o el "sonido Poleva", de Tavener. Todos los cuerpos, nos dice Einstein, son deformables, alteran su volumen, no son rígidos, etc. (en un estilo muy nietzscheano; creemos que el filósofo es fundamento de estas ideas contemporáneas). Los cuerpos mismos son artefactos técnicos (como piensa J.L. Nancy en su breve pero memorable e in- 
tenso texto autobiográfico de "El intruso" (2006), esto es, mediaciones, intersticios, mesetas, notas, pliegues, impresiones, esto es, los cuerpos mismos antes de ser cuerpos, y para ser propiamente cuerpos, son devenires, flujos, dinamismos, vórtices, intensidades, etc. Entonces, tenemos que cuando es la propia concepción de las cosas la que cambia, también cambia radicalmente lo que sea la materia y con ello el Otro (esto es fundamental tenerlo bien claro en la historia del pensamiento). Al modular lo que son las cosas ya no será lo mismo la articulación materia y Otro y en estos los sonidos e imágenes van a adquirir una dimensión material con el cual se puede trabajar (eso es entre otras cosas el "dripping” del pintor Jackson Pollock). Pero ¿cómo se modulan las cosas?

Realizar la distinción entre materia y materialidad es muy útil para nuestra propuesta en torno al arte de Poleva, en torno al "sonido Poleva” y al trabajo de la gran artesana ucraniana con el sonido. Un pensamiento que se mueve en cartografías piensa desde el "afuera" desde dónde se dan los modos de estar siendo en el mundo, pero un "afuera" totalmente embargado en las mediaciones mismas del pensar (no es un afuera por el "Afuera Mismo”). Esto permite el juego de los intersticios rizomáticos y dinamizar las categorías (hacerlas sentientes). Lo dicho aunque parezca algo superfluo es muy importante, porque de inmediato nos separa el carácter de cuerpo de su propio fundamento (por hablar de algún modo): la corporeidad (estamos en la línea de pliegues, como diría Deleuze, en tanto des-pliegues como re-pliegues (DELEUZE, 2000). En esto se elimina de raíz un problema clave en las interpretaciones de la materia.

El cuerpo espacial (y obviamente temporal) no es radicalmente un absoluto como lo era pensado por Newton (1987) y, por tanto, las cosas no solamente ocupan un lugar en él (no tiene sentido ya pensarlo así). Dicho esto, tampoco podríamos decir que el Otro es un absoluto de algún tipo (esto se tiene que matizar), algo así como si fuera éste un recipiente transcendental desde donde el hombre se constituye como hombre, por eso era fácil para la teología (y filosofía) pensar a Dios de esta manera; en cambio, el arte de Poleva y Tarkovsky expresan lo otro en tanto que Otro que se abre desde el propio espacio sonoro y de tiempo fijado por el artista. Un espacio sonoro que no es el espacio físico típico del ámbito de lo común; ese espacio abierto por el sonido material, es más cercano a la experiencia de las olas o de los delfines o cetáceos superiores que en su estar en medio del mar se mueven por medio de sonidos que diseñan los caminos y lugares por donde ir. Las capillas y catedrales que diseña la arquitecta sonora material Poleva tienen esa dimensión, no se quedan en la mera transfiguración del lugar donde acontece la experiencia auditiva de escuchar una de sus obras, sino que el edificio material diseñado por Poleva puede estar a miles de kilómetros reales de distancia (no hay barrera empírica que pueda con las obras arquitectónica de ella). Es una construcción que acontece en la materialidad del sonido, no hay catedral que pueda con ella, ni la imponente Catedral de Chartres (o su querida Catedral de Kiev); incluso esta Catedral es diminuta con las pequeñas, bellas, minimalistas y preciosas capillas del "sonido Poleva" que configuran lo sacro. La iteración del sonido, su elevación, entre esos silencios que siempre vuelven hacen volver la sensación, pero de modo distinto (así como la poesía de Kavafis (1981). De allí su trabajo coral y el tratamiento de la voz y las voces (y su "y" que las articula), permite que sus capillas rompan con lo físico y se sumerjan en lo inconsciente y se eleven a lo virtual (DELEUZE, 2000).

Y si analizamos su mano que esculpe tiempo, lo hace de forma magistralmente precisa (con la precisión de un Ozu para componer los planos o de Durero para diseñar sus animales). En este tiempo preciso se esculpe el sonido de lo otro, en ese tiempo siempre eterno retornante se abre la eternidad a cada instante. La música es siempre jovial (y esto no lo puede la imagen ni Tarkovsky). Es como si en esa obra estuviera toda la eternidad conteni- 
da, por un lado finita y la vez infinita (el sueño de Hegel lo realiza la música, esta música); es la música de Poleva y en esto su trabajo del tiempo es muy cercano y similar al gran trabajo de la imagen tarkovskiana. Las imágenes en su finitud mientan, indican infinitud. Las imágenes de Tarkosvky son "transfinitas", así como los sonidos Poleva. Y no es el tiempo del reloj, es el tiempo del sonido y de la imagen. El tiempo del sonido en su duración da impronta, sentido y color a esa capilla de lo sacro ya diseñada por la compositora ucraniana. La capilla se llena de colores y brilla gracia a ese tiempo de lo sonoro. Cuando se está ante la presencia sonora dePsalm 50 nos quedamos viviendo en esa capilla resplandeciente del sonido y quedamos espiritualizados en ese lugar temporal del sonido. Y la realidad mundanal queda completamente elevada por ese lugar de lo sacro. Es importante señalar que los espacios-tiempos sacros del sonido como de la imagen perforan todo espacio profano en donde se le habita.

De este modo, pareciera ser que el sonido esta cubierto por dos arquetipos, pero al mismo tiempo, no existen en realidad dos tipos de arquetipos. Ambos son absolutos en su existencia. El arquetipo se mueve un paso más allá y posee en sus valores pre-racionales el plan para su realización material. El primer tipo, a pesar de que contiene todas las posibilidades posteriores, es sólo el impulso para las realizaciones previas de sonido mientras que el segundo es la causa directa de ellos. Sin embargo, los arquetipos del segundo tipo tienen latentes en su interior, aunque no totalmente realizable, la energía y las estructuras universales del arquetipo inicial. El valor del sonido físico, como una energía específica muy clara, son los cambios del estado del oyente y esta energía se pone en marcha en una resonancia con las vibraciones no-materiales con las que el sonido tiene en su origen.

A veces los artistas como ellos no solamente nos hacen bien, sino que además crean mundo, "más mundo" en este pequeño mundo en el que habitamos. Nos crean mundo inconsciente, mundo virtual, mundo para soñar, mundo para esperar, mundo para meramente sentir y hospedar al otro, cualquier otro; mundos para amar.La música contemporánea y el cine (también la plástica, etc.) han realizado un gran trabajo con el sonido y la imagen en su trato con lo Otro. El espacio-tiempo (material) y el Otro hoy se entiende de otra forma. $\mathrm{Y}$ en esto cierto cine con su trabajo formal de la imagen ha realizado un gran logro, es cosa muy simple de analizar las obras, por ejemplo, de Welles, Ozu, Dreyer, Bresson o Tarkovsky (por nombrar algunos cineastas) para ver cómo en la imagen misma acontece lo Otro; o en la música contemporánea lo mismo, pensemos en Pärt, Tavener, Preisner, Gorecki o Poleva (por nombrar algunos compositores); aquí ya no se da la necesidad, algo infantil, de "representar" eso Otro en la imagen o el sonido, como si eso Otro fuera "algo concreto". Por eso pensar este problema de la materia, no ya desde ese carácter de mero cuerpo espacioso como recipiente, nos permite, a la vez, estar pensando lo que sea el Otro. Lo que vamos diciendo del cuerpo lo podemos ir, de alguna manera, pensando para el Otro.

Si entendemos la materia desde la materialidad podemos ver que hay múltiples modos de estar en los límites de la materia, entre los sonidos-imágenes (es el gran proyecto de Bergson que luego realiza Deleuze a lo largo de su vida de modo magistral). Pensar la materia y el Otro desde el espacio-tiempo nos permite pensar modos distintos de entender esa "Y" que los articula. Y en esto el arte, como el de Poleva, lo permite realmente.

\section{Arte y nosotros}

El hombre y su materia eso es el arte con mayúscula; esa "y" que los coordina se expresa en el trabajo del artista de la materialidad y la trascendencia por medio del sonido y la imagen: Poleva-Tarkovsky. Así es como el otro se muestra como Otro, pero no por 
fuera de sí mismo, sino en sí mismo. El Otro abre cuerpo espacioso a un Nosotros, pero es el Nosotros el que está siendo a la vez en ese abrir cuerpo espacioso (estamos en un pensamiento articulador, pero no dialéctico; se articula físicamente sin negatividades ni cosas por el estilo) por eso estamos de la mano de Nietzsche, Deleuze, Zubiri, Heidegger, Tarkovsky y Poleva: estamos pensado el mostrarse somático corporal del Otro, pero donde se da por excelencia este mostrarse es tanto en el cine como en la música; este es el lugar actual propio de la imagen y del sonido (pensamos que hoy no es la fotografía el lugar de la imagen). El Otro, aparentemente, está ahí en articulación con Nosotros, está ahí siendo definido, acotado, determinado, destinado por el Nosotros, el Otro está ahí meramente estando ahí en co-presencia corporal y somática con el Nosotros en imágenes y sonidos, pero todos estos juegos son posibles porque en el fondo, en el cuerpo más propio del Otro, se da que el Otro es un Múltiple (múltiples capas, pliegues, sensaciones, estofas), es ya un Nosotros; una mónada es solamente mónada activa en y por sí misma desde el todo de las mónadas (la armonía pre-establecida (LEIBNIZ, 2001). iQuedémonos con esto! En verdad, si nos damos cuenta no tiene ya sentido preguntarse por un otro cualquiera y menos por el Otro sin más por fuera de nuestras sensaciones, tiene tan poco sentido como preguntarse por un nosotros corporal somático tal o cual o un Nosotros sustantivado como si fuera algo concreto. En el Nosotros ya resuenan los Otros unos con Otros. Y esto en el arte de Poleva no solamente queda claro por su modo de componer o por su trabajo coral y sinfónico o por el uso de ciertas materialidades en articulación con el espacio y tiempo, sino que es evidente en el Otro mismo que acontece ante sus obras. Se le despliega una arquitectónica del espacio y se le esculpe un tiempo, en ese espacio-tiempo ya no está solo sino junto a otros, nos volvemos múltiples, en el fondo, devenimos comunidad. Y esa articulación de unos con otros, ese devenir comunidad, es lo que intentamos pensar rizomáticamente desde el arte de Poleva y Tarkovsky; es el modo de presentarse ese uno en y por el Otro, en tanto el Otro es en y por el uno, pero mejor dicho, pensarlo desde la imagen, desde el cine, desde el sonido, desde la música.

El Nosotros desde la articulación Nos-Otros nos permite quedarnos en semejante co-actualidad, un devenir comunidad físico entre todos. Esa co-actualidad en su carácter físico, de cuerpo ("sin órganos”) se sistematiza y en ese juego cada uno se organiza como imagen y sonido (en un plano y en una partitura), esto es, una cierta infinitud finita, un pliegue; como una gran Catedral Barroca (barroco en sentido amplio, al estilo de Deleuze, más allá de una determinación estilística y epocal), pero en tanto Catedral "fragmentaria" (como la Sagrada Familia de Gaudí); la que en su aparentemente inconexión de pliegues imaginativos sonoros somáticos está abierta a distintas determinaciones que siempre están en obra desde lo mismo; la Catedral como un Múltiple que se abre en la misma medida que se cierra, que se abre en la mirada de una persona, de un pueblo, de un época, pero en esto mismo siempre al borde, en el límite de cerrarse por siempre. Todo individuo, todo pueblo, toda época siempre está al borde de sumergirse en el ocaso y esto entre otras cosas es porque tanto el individuo como un pueblo y una época son un Más, un Múltiple que se excede en sí mismo. Este rasgo de suyo individual-abierto de las impresiones, de ese carácter físico que articula como un pliegue, como un punto nos ayuda a comprender la materia "Y" el Otro. Poleva constructora de catedrales y escultura de lo infinito nos da la mano para habitar en otro mundo de la sensación que nos vuelve comunidad en medio de este mundo tardo-capitalista narciso y competitivo en el que habitamos en radical soledad. El "sonido Poleva" y la imagen tarkovskiana nos instaura en la misma sensación de la materia y allí nos deja posibilitados para poder vivir corporalmente unos con otros espiritualizados y con ansias de algo mejor. 


\section{Nueva lógica creativa}

Si nos hemos dado cuenta a lo largo de todo este escrito, estamos ante una nueva lógica (a través de ciertas categorías de Nietzsche, Heidegger, Zubiri, Deleuze) que en el film Nostalgia de Andrei Tarkovsky (así como en Psalm 50de Poleva) cobran real significación; pues es en el cine en general y en el cine de Tarkovsky en especial donde lo dicho por los filósofos, por medio de sus conceptos, se realiza corporalmente, se somatiza, se expresa en la radicalidad de la imagen. Tenemos que esperar la evolución de la obra de Poleva para ver cómo se dará su legado (pues de Tarkovsky ya nos ha quedado claro el acontecer de su obra). A lo mejor puede ser similar, en algún aspecto, al del cineasta ruso, pero en lo sonoro. Y ahí todavía hay mucho que hacer, explorar y abrir. Poleva está en plena arquitectónica del espacio sacro y esculpiendo tiempo eterno para donar mundos habitables y así es posible que se den nuevas comunidades. En Tarkovsky ya hay un legado clarísimo, este es uno de sus más grandes aportes no solamente al arte sino a la vida en su cotidianidad y no olvidemos que solamente realizó siete films. Su cine puede y realiza lo que la filosofía meramente intenta e indica; esto es, el concepto se queda por "afuera" de lo que la imagen indica desde "dentro" en su interioridad espacio-temporal. Y en la música, creo, que aún es más radical; ella está en la piel misma de la realidad en su espacio-tiempo y además es eternamente retornante y por ello jovial, esto es, siempre sensitiva, siempre. El concepto, donde se mueve el filósofo, es un "afuera” de la sensación, materialidad y comunidad; porque es el bosquejo categorial de entender al Otro en su aparecer somático en múltiples trazas de articulación; aparecer, en cambio, que en la imagen fílmica es siempre en y por sí misma, lo somático que expresa el cuerpo y el otro en tanto que nosotros mismos somos perturbado en tanto cuerpo por dicha imagen (y en el sonido es todavía más radical).

En el cine de Tarkovsky lo que hemos señalado es por lo general así. Su imagen tiene la capacidad de llegar a la cosa misma que el concepto tiende solamente a describir y señalar desde lejos. Su cine es de imagen en y por sí misma. Y en tal cine se da una lógica de la imagen que mienta el aparecer mismo somático corporal en trama técnica arquitectónica y escultórica, pero única; la imagen en general y, la tarkovskyana en especial, es una imagen somática que siempre se da en un aparecer que se constituye de múltiples momentos para ser completamente un Acontecimiento: el paso de la infinitud que nos da la posibilidad de habitar en comunidad. Y esos momentos se articula la totalidad. Por eso ese cine es de experiencia interiorizante que expresa la totalidad desde ciertos puntos o momentos articulados, los cuales mientan al otro en tanto que Otro y en la propia materialidad de la sensación.

En el film Nostalghia, por ejemplo, de Tarkovsky se indica por medio de un estremecedor plano lo que hemos intentado mostrar a través de la filosofía y por medio de muchos momentos descriptivos de las categorías (cuerpo, espacio, tiempo, otro, soma, etc.); en un plano del Film se muestra una sumatoria que no suma, sino que "Aglutina” uno y otro, otro y uno en excedencia; esto es, el Cuerpo y el Otro (la base misma de su cine y a la vez del arte de composición de Poleva):

$$
1+1=1
$$

En este Film un emotivo loco italiano, que busca dar sentido al mundo (y en esto, salvarlo, a través de un sacrificio), indica a un sombrío escritor ruso que ya no hay sentido alguno del mundo; éste se ha perdido pues le falta fe. Y le muestra cómo se agencia el ter- 
ritorio de la fe, de la creación, del sacrificio para que el hombre pueda territorializar su vida desde lo más propio de su ser mortal. Ese acontecimiento es encender una simple vela y portarla a través de una terma vacía de un lado al otro; este simple acontecimiento abre un agenciamiento territorializante de la vida (una arquitectónica); genera una imagen sacra del mundo. Pues iqué acontece en ese aparentemente hecho inocuo y absurdo de encender una vela y caminar por una antigua terma italiana que se encuentra vacía de un lado al otro y en la total soledad sin que esta vela se apague? Lo que hay es la posibilidad de re-territorializar un espacio y volverlo nuevamente propio (el "sonido Poleva” hace lo mismo). Y señala, el loco al escritor, que en el simple hecho de encender una vela ya es en sí mismo encender otra vela y otra vela, etc. Es la nueva lógica existencial del sacrificio que nos salva a todos de la barbarie del modo de vida alienante en el que somos. Allí en ese espacio sacro del movimiento de la cámara en un plano secuencia perfecto, se esculpe tiempo y acontece la eternidad. Es una lógica nuevamente cercana a Deleuze, esto es, en iteración y aglutinamiento: 1 más 1 y más 1 es 1, pero un 1 más robusto, más integrado, de todos los momentos, de todas sus voces, de todas las imágenes, de todos, de nosotros. Y así ya nos hemos salvado, pues hemos dado con el sentido de la eternidad en el instante somático del presente corporal en el hecho gratuito de encender una vela; en esa estofa material precisa del fuego (es el tiempo). Una vela encendida ya es en sí misma co-actual con otras velas encendidas (la comunidad), todas se presentan en una trama de velas se organizan como tales (es un múltiple que funda comunidad), están siendo ya en su individualidad-como social e histórica, como fractales, como fragmentos autosimilares a la vez; en el espaciar mismo de la luminosidad de sus aglutinaciones de unos con otros en transfinitud. Preguntarse por el Otro, por la materia solamente es posible si preguntamos por la materia y el Otro. Y nos detenemos en esa "Y" que los entrecruza y los liga el uno al otro en un Nos-Otros. Y en ese Cruce, la lógica que los suma es distinta, es por "Acumulación”, como ya se ha señalado. Una gota de aceite más otra gota de aceite es una gota de aceite más grande, más expandida, más extensa, más trascendental (esto es la sensación estética de la imagen y del sonido); otro más otro es otro (un Nos-Otros), pero solamente se da otro junto a otro "otro" y junto a otro "otro", etc.; son Otros en capas de pasado, puntas de presente, series de futuro, en pliegues monádicos, en imágenes-tiempo, en ritornelos, en modos de Aion, en arquitecturas de lo sacro, en imágenes-conciencia, en cosas-inteligencia, en co-actualidad, en comunidad. De allí que en esta lógica del tiempo de la materia y el Otro, por medio del arte del sonido y de la imagen, ya no tiene sentido entender la verdad como adecuación, sino en perspectivas ya sonantes como disonantes, en Múltiples pliegues que se despliegan y se repliegan en su simplicidad y complejidad.

\section{Conclusión}

Es posible que en la actualidad, en la co-actualidad de sonido-imagen y hombre, de cosa e inteligencia, de hombre y su materia, de materia y Otro, sea el Cine y la Música y no la Metafísica (ni la ética, ni la política, ni la poesía, ni la plástica, etc.) quién tenga más posibilidades de dar señales, de dar indicios, de abrir caminos reales para el otro, en tanto materia y Otro. Un Sonido-Imagen es capaz hoy, más que nunca, de dar, a muchos de nosotros, performativos para poder situarnos más cómodamente en un nuevo mundo. Y el sonido Poleva es ya una realidad de ese carácter performativo que nos espiritualiza, nos dona el mundo de lo sacro y nos hace acceder jovialmente a los territorios de la eternidad. 


\section{Nota}

1 Este artículo es parte del Proyecto Fondecyt N 1170454: "Realidad y técnica en Zubiri”.

\section{Referencias}

ANGELOPOULOS, Theodoros. La eternidad y un día. Grecia/Francia/Italia: Paradis Films/Intermedias/La Sept Cinema,, 1998

BERGSON, Henri. Materia y Memoria. Buenos Aires: Ed. Cactus, 2006.

DELEUZE, Gilles. El pliegue. Leibniz y el barroco. Madrid:Paidos, 2000.

; GUATTARI, Félix. Mil mesetas. Valencia: Pre-Textos, 2000.

DUQUE, Félix. Filosofía para el fin de los tiempos. Tecnología y apocalipsis. Madrid: Akal, 2000.

EINSTEIN, Albert. Mis ideas y opiniones. Barcelona: Antoni Bosch, 1990.

. El logos nominal constructo en el pensamiento de Zubiri. The Xavier Zubiri Review, USA, v. 3, p. 29-57, 2000/2001.

.En torno al problema del Ereignis... Das Ereignisereignet das Sein. Revista Philosophica, Valparaíso, v. 28, p. 61-92, 2005.

. Flashback, miradas y gestos. Concón: Midas, 2012.

. Realidad y tiempo en Zubiri. Granada: Comares, 2006.

ESPINOZA, Ricardo et al. Cuerpo y espacio. Reflexiones sobre una topología de la exterioridad. Filosofia Unisinos, v. 15, n. 3, p. 237-248, sep./dec. 2014.

HEGEL, Georg Wilhelm.Friedrich. Enciclopedia de las ciencia filosóficas. Madrid: Alianza, 1997. . Fenomenología del espíritu. México: FCE, 1966.

HEIDEGGER, Martin. Aportes a la filosofía. Acerca del evento. Buenos Aires: Almagesto-Biblos, 2003.

. Beiträgezur Philosophie. Frankfurt am Main: Vom Ereignis. Klostermann, 1989.

. Observaciones relativas al arte - la plástica - el espacio / El arte y el espacio. Navarra:

Universidad Pública de Navarra, 2003. (Ed. Trilingüe: Alemán, Castellano, Euskera).

. Ser y tiempo. Santiago de Chile: Ed. Universitaria, 1997.

. Tiempo y ser. Madrid:Tecnos, 1999.

HILLIER, Paul. Arvo PärtOxford Studies of Composers. New York: Ed. Oxford University Press, 1997.

KAVAFIS, Konstantino. Poesías Completas. Madrid: Hiperion, 1981.

LEIBNIZ, Gottfried Wilhelm. Monadología. Biblioteca Nueva, 2001.

LLANO, Rafael. Andrei Tarkovski. Vols. I y II. Generalitat Valencia: Valenciana, 2003.

NANCY, Jean-Luc. El Intruso. Barcelona: Anagrama, 2006.

NEWTON, Isaac. Principios Matemáticos de la Filosofía Natural. Madrid: Alianza , 1987. 
NIETZSCHE, Friedrich. Así habló Zaratustra. Madrid: Valdemar, 2005.

El nacimiento de la tragedia. Madrid: Biblioteca Nueva, 2007.

. Obra selecta. Madrid: Gredos, 2009.

POLEVA, Victoria. Gagaku. Ballet sobre la historia "Hell Screen” de Ryūnosuke Akutagawa. Para orquesta de cámara, Kiev, 1994.

. Metta-in modo Pärt-Para flauta (violín), vibráfono y orquesta de cuerdas, Kiev,2009.

. No manisan Island. Cantata de cámara sobre textos de John Donne. Para mezzo solista, coro femenino, piano y orquesta de cuerdas, Kiev, 2006

. Psalm 50. Para coro mixto, Kiev, 2000.

TARKOVSKY, Andrei. Esculpir en el tiempo. Madrid: Rialp, 2008.

VIOLA, Bill. Reasons for Knocking at an Empty House. Cambridge: The MIL Press, 1995.

ZUBIRI, Xavier. Espacio. Tiempo. Materia. Madrid: Alianza, 1996.

Ricardo Espinoza Lolas - Doctor en Filosofía por la Universidad Autónoma de Madrid. Catedrático de Historia de la Filosofía Contemporánea en el Instituto de Filosofía de la Pontificia Universidad Católica de Valparaíso, Chile.

Boris Alvarado - Doctor en Composición Musical en la Academia de Música Fryderyk Chopin de Varsovia. Catedrático de Análisis, Polifonía, Composición, Armonía, Instrumentación, Orquestación y Seminario para compositores del Instituto de Música de la Pontificia Universidad Católica de Valparaíso, Chile

Patricio Landaeta Mardones - Doctor en Filosofía por las universidades Pontificia Universidad Católica de Valparaíso, Universidad Complutense de Madrid (mención Doctorado Europeo), y por la Universidad de Paris 8 Vincennes-Saint-Denis. Investigador en el Centro de Estudios Avanzados (CEA) de la Universidad de Playa Ancha, Valparaíso, Chile. 